\title{
International cartographic education progress: a bibliometric analysis of ICCs literature
}

\author{
Tao Wang ${ }^{\mathrm{a}, *}$, Minghui Sun ${ }^{\mathrm{b}}$ \\ ${ }^{a}$ School of Resource Environment and Tourism, Capital Normal University, China,wangt@cnu.edu.cn \\ ${ }^{b}$ School of Resource Environment and Tourism, Capital Normal University, China, 2200902183@cnu.edu.cn \\ * Corresponding author
}

Keywords: Cartography, geographic information science, education and training, online learning, Citespace

\begin{abstract}
:
Education and talent training are the cornerstones of the development of cartography and geographic information science, as a discipline and a profession. Educators and researchers have made great and continuous efforts in designing new courses and building programmes for this purpose. In the new normal era of post-Covid19, summaries and reflections of the progress of experience and theories can help to design sustainable and resilient education practice and new model of talent training. In this work, the conference papers and abstracts on educational topics of the International Cartography Conferences in the past two decades are used as a data source. Bibliometric analysis is employed to develop a thorough overview of publications on education topics in the last ten International Cartographic Conferences. A bibliometric software, namely CiteSpace, is used to carry out thematic analysis of education topics, authors, and regions. A domain term knowledge map is drawn. The results show that the number of publications on education in the International Cartography Conferences has been increasing. Authors from Brazil, the United States, Germany, Russia and Switzerland are the top five countries contributing about $40 \%$ publications in this field. In general European countries contribute about $50 \%$ publications. The research topics are mainly focused on undergraduate and graduate education in geographic information systems, secondary education, education atlas, learning theories, learning environmental design, online education, etc. Pedagogies and experience of distance learning and online education in the last 20 years have been well applied as a new normal of education in the context of Covid19 global pandemics.
\end{abstract}

